\title{
Mouth Mucous Membrane Leukoplakia
}

National Cancer Institute

\section{Source}

National Cancer Institute. Mouth Mucous Membrane Leukoplakia. NCI Thesaurus. Code C7743.

A clinical term that indicates the presence of a white patch on the mucous membrane in the mouth which cannot be characterized as any other disease. It may be a precancerous condition and in most cases histologic examination reveals keratosis. 